\title{
Sistem Pendukung Keputusan Pemilihan Kepala Desa Terbaik Menerapkan Metodethe Extended Promethee II (EXPROM II)
}

\author{
Nurlela, Muhammad Syahrizal, Fadlina, Abdul Karim \\ Program Studi Teknik Informatika, STMIK Budi Darma, Medan, Indonesia \\ Email:nurlela66@gmail.com
}

\begin{abstract}
Abstrak-Sistem Pendukung Keputusan merupakan sistem yang dapat membantu manajemen dalam mengambil suatu keputusan yang tepat, yang di perlukan dalam suatu tingkat manajemen. Begitu pula pada Kantor Camat Lubuk Pakam dalam melakukan pemilihan kepala desa terbaik. Selama ini Kantor Camat belum pernah menentukan kepala desa terbaik yang terdapat pada Kecamatan Lubuk Pakam sehingga menemui kendala dalam melakukan pemilihan kepala desa tersebut. SPK mampu memberi alternatif solusi bagi masalah semi/tidak terstruktur baik bagi perseorangan atau kelompok dab dalam berbagai macam proses dan gaya pengambilan keputusan, SPK menggunakan data, basis data dan analisa model-model keputusan. Melihat hal tersebut peneliti tertarik untuk melakukan penelitian dengan menerapkan metode The Extended Promethee II (EXPROM II) untuk melakukan pemilihan kepala desa terbaik dalam suatu sistem pendukung keputusan. Diharapkan hasil penelitian dapat membantu pihak kecamatan Lubuk Pakam.
\end{abstract}

Kata Kunci: SPK,Terbaik, Kepala Desa, EXPROM II.

Abstract-Decision Support System is a system that can help management in making the right decision, which is needed at a management level. Likewise at the Lubuk Pakam Sub-District Office in selecting the best village head. So far, the Camat Office has never determined the best village head in Lubuk Pakam Subdistrict, so that it encounters obstacles in choosing the village head election. SPK is able to provide alternative solutions to semi / unstructured problems for individuals or groups and in a variety of decision making processes and styles, SPK uses data, databases and analyzes of decision models. Seeing this, researchers are interested in conducting research by applying the Extended Promethee II (EXPROM II) method to elect the best village head in a decision support system. It is expected that the results of the research can help the Lubuk Pakam subdistrict.

Keywords: SPK, Best, Village Head, EXPROM II.

\section{PENDAHULUAN}

Sistem Pendukung Keputusan adalah sebuah sistem berbasis komputer dengan antarmuka antara mesin/komputer dan pengguna. Sistem Pendukung Keputusan ditujukan untuk membantu pembuat keputusan dalam menyelesaikan suatu masalah dalam berbagai level manajemen dan bukan untuk mengganti posisi manusia sebagai pembuat keputusan. SPK mampu memberi alternatif solusi bagi masalah semi/tidak terstruktur baik bagi perseorangan atau kelompok dan dalam berbagai macam proses dan gaya pengambilan keputusan, SPK menggunakan data, basis data dan analisa model-model keputusan. SPK pemilihan kepala desa ini menggunakan metode The Extented Promethee II (EXPROM II). The Extented Promethee II (EXPROM II) merupakan Sebuah indeks preferensi total dihitung dengan menambahkan nilai indeks preferensi yang lemah dan kuat yang memberikan ukuran yang akurat dari preferensi satu alternatif dengan alternatif yang lain untuk semua kriteria.

Kepala Desa adalah pemimpin dari pemerintahan di tingkat desa di Negara Indonesia. Masa jabatan Kepala Desa adalah 6 (enam) tahun, dan dapat diperpanjang lagi untuk satu kali masa jabatan berikutnya. Kepala Desa tidak bertanggung jawab kepada Camat, namun hanya dikoordinasikan saja oleh Camat. Kepala Desa dilarang menjadi pengurus partai politik (namun boleh menjadi anggota partai politik), Kepala Desa dapat diberhentikan atas usul Pimpinan BPD kepada Bupati/Walikota melalui Camat, berdasarkan keputusan musyawarah BPD[1].

Permasalahan pemilihan kepala desa pada kec. Lubuk pakam, dipilih berdasarkan kriteria yaitu beberapa yang ditentukan oleh pihak kecamatan, namun permasalahan yang sering muncul adalah didalam proses pemilihan kepala desa masih ada berhubungan dengan pihak kecamatan dan terkadang ada juga yang seharusnya terpilih dan tidak terpilih hanya dikarenakan kurangnya pendekatan dengan masyarakat desa. Kelemahannya adalah masyarakat tidak mengenal sosok kepala desanya yang dipilih. Oleh sebab itu untuk memecahkan masalah tersebut, penulis mengenalkan dengan menggunakan sistem pendukung keputusan. Maka dari setiap kriteria pemilihan berdasarkan kriteria diantaranya dari segi kemampuan, segi sosialisasi, segi pergaulan, segi bermasyarakat dan segi kepribadian. Untuk mengatasi kelemahan tersebut maka dibutuhkan pemilihan berdasarkan kriteria yang nantinya menjadi kepala desa. Alasan menggunakan sistem pendukung keputusan karena merupakan suatu alternatif sistem yang interaktif guna membantu mengambil keputusan melalui penggunaan data dan model-model keputusan untuk memecahkan masalah yang bersifat semi terstruktur maupun yang tidak terstruktur menurut Haniif (2007). Maka dari itu penulis berusaha membuat sebuat sistem pendukung keputusan untuk membantu pemerintah daerah untuk menyeleksi kepala desa serta warga masyarakat dalam memilih suatu pemimpin desa yang sesuai dengan syarat dan kriteria-kriteria yang ditentukan.

Berdasarkan penelitian sebelumnya yang dilakukan oleh Jorry Karim, Jurnal Ilmiah, STMIK Ichsan Gorontalo, Tahun 2018, Volume 10, No.1, April, yang mengangkat tentang Sistem Pendukung Keputusan Penentuan Prioritas Pembangunan Menggunakan Metode Promethee Pada Desa Ayula Kecamatan Randangan Kabupaten Pohuwato Provinsi Gorontalo menyatakan Penelitian ini adalah salah satu metode penentuan urutan 
atau prioritas.Sistem inidirancang menggunakan bahasa Pemrograman PHP dengan Database MySQL, untuk membuatkan sebuah sistem pendukung keputusan baru yang berbasis komputerisasi yang merupakan salah satu alternatif yang baik dengan mengedepankan efektifitas dan efisien dalam Penentuan Prioritas Pembangunan [2].

Ahmad Gazali, Rintana Arnie, Jurnal Program Studi Sistem Informasi STMIK Banjarbaru, Tahun 2016, Volume 05, No.1, April, yang mengangkat tentang, Model Sistem Pendukung Keputusan Pemilihan Desa Terbaik Menggunakan Metode Weighting Product menyatakan Penelitian ini adalah merancang suatu sistem pendukung keputusan yang dapat menentukan desa terbaik dalam lomba desa yang dilakukan oleh Badan PemberdayaanMasyarakat dan Pemerintahan Desa serta memberikan hasil perhitungan yang sudah sesuai dengan aturan yang sudah ditetapkan oleh menteri dalam negeri nomor 13 tahun 2007 menggunakan metode Weighting Product. Metode Weighted Product (WP) Metode WP merupakan salah satu metode penyelesaian yang ditawarkan untukmenyelesaikan masalah Multi Attribute Decision Making (MADM). Metode WP mirip dengan Metode Weighted Sum (WS), hanya saja metode WP terdapat perkalian dalam perhitungan matematikanya [3].

Pada kasus ini dibahas tentang penerapan The Extented Promethee II (EXPROM II) untuk penentuan produk diskon. Memberikan hasil bahwa Penentuan produk diskon harus dilakukan dengan pertimbangan dan perhitungan yang tepat. Sistem Pedukung Keputusan (SPK) dapat membantu pimpinan swalayan dalam mengambil keputusan untuk menentukan produk diskon yang tepat dan meningkatkan efesiensi keputusan tersebut. The Extended Promethee (EXPROM II) merupakan salah satu metode penentuan urutan atau prioritas dalam analisis multikriteria. EXPROM II membandingkan alternatif yang satu dengan alternatif yang lainnya dan menghitung jarak selisih alternatif berpasangan sehingga menghasilkan output yaitu perangkingan alternatif berdasarkan nilai net flow tertinggi. Penentuan produk diskon yang tepat dan efektif memberikan dampak positif untuk swalayan karena dapat meningkatkan penjualan secara keseluruhan [4].

\section{METODE PENELITIAN}

\subsection{Sistem Pendukung Keputusan}

Sistem Pendukung Keputusan Decision Suppor Sistem (DSS) merupakan sistem informasi interaktif yang menyediakan informasi, pemodelan, dan pemanipulasian data. Aplikasi Decision Suppor Sistem (DSS) menggunakan data, memberikan antarmuka pengguna yang mudah, dan dapat menggabungkan pemikiran pengambilan keputusan. Pendekatan sistem yang merupakan kumpulan dari elemen-elemen atau komponenkomponen atau subsistem-subsistem merupakan defenisi yang luas.Defenisi ini lebih banyak diterima, karena kenyataan suatu sistem dapat terdiri dari beberapa subsistem atau sistem bagian lainnya[5]-[9].

\subsection{The Extended Promethee II (EXPROM II)}

The Extended Promethee II (EXPROM II) yang dikembangkan oleh Diakoulaki dan Koumoutsosa adalah versi modifikasi Promethee IIyaitu perbandingan deviasi atau jarak antar alternatif berpasangan untuk setiap kriteria. EXPROM IImenghasilkan perangkingan alternatif berdasarkan nilai net flowsetiap alternatif sehingga memberikan alternatif terbaik dengan net flow tertinggi[10]-[13]. Algoritma dalam penyelesaian Sistem Pendukung Keputusan (SPK)dengan metode EXPROM II [4], [13]-[16], antara lain:

1. Membuat Matriks Keputusan.

Matriks keputusan adalah matriks yang terdiri dari nilai alternatif $i$ untuk setiap kriteria $j$.

2. Normalisasi Matriks Keputusan.

Untuk jenis kriteria benefit:

$\mathrm{rij}=\frac{[\mathrm{xij}-\min (\mathrm{xij})]}{[\max (\mathrm{xij})-\min (\mathrm{xij})]}(\mathrm{i}=1,2, . ., \mathrm{m} ; \mathrm{j}=1,2, . . \mathrm{n})$

Untuk jenis kriteria cost:

rij $=\frac{[\max (x i j)-x i j]}{[\max (x i j)-\min (x i j)]}$

Dimana:

$r i j=$ matriks ternormalisasi

$\mathrm{i}=$ alternatif

j = kriteria

3. Penentuan Fungsi Preferensi $P j\left(i, i^{\prime}\right)$.

Ada enam jenis fungsi preferensi yang utama, misalnya, kriteria biasa, kriteria bentuk $\mathrm{U}$, kriteria bentuk V, kriteria tingkat, kriteria pengabaian bentuk V dan kriteria Gaussian. Bentuk yang paling sederhana dari fungsi preferensi (kriteria biasa) diterapkan di sini, persamaan Fungsi Preferensi $\operatorname{Pj}\left(i, i^{\prime}\right)$ diberikan di bawah ini:

$\operatorname{Pij}\left(\mathrm{i}, \mathrm{i}^{\prime}\right)=0$ if $\mathrm{rij} \leq \mathrm{ri}{ }^{\prime} \mathrm{j}$

$\operatorname{Pij}\left(i, i^{\prime}\right)=($ rij-ri'j) if rij $>$ ri'j

dimana :

Pij = Fungsi Preferensi

i =alternatif 
$i^{\prime} \quad$ =alternatif yang akan dipasangkan

4. $\quad$ Menghitung Nilai Weak Preference (WP)

Perhitungan indeks preferensi yang lemah dengan mempertimbangkan kriteria dengan nilai bobotyang berbeda-beda untuk setiap kriteria menggunakan persamaan berikut:

$\mathrm{WP}\left(\mathrm{i}, \mathrm{i}^{\prime}\right)=[\Sigma \mathrm{wj} \times \mathrm{Pj}(\mathrm{i}, \mathrm{i}) \mathrm{nj}=1] \sum \mathrm{wjnj}=1 /$

dimana : WP $=$ Weak Preference

$\mathrm{n}=$ jumlah kriteria

$\mathrm{wj}=$ bobot kriteria $\mathrm{j}$

5. Menghitung Nilai $\operatorname{SP} j\left(i, i^{\prime}\right)$.

Menentukan fungsi preferensi yang kuat $S P j\left(i, i^{\prime}\right)$. Fungsi preferensi yang kuat berdasarkan perbandingan nilai-nilai perbedaan $(d m j)$ dengan rentang nilai seperti yang didefinisikan oleh evaluasi dari seluruh rangkaian alternatif untuk kriteria.

$\operatorname{SPj}\left(\mathrm{i}, \mathrm{i}^{\prime}\right)=[\max (0, \mathrm{dj}-\mathrm{Lj})] /[\mathrm{dmj}-\mathrm{Lj}]$

Dimana: $\mathrm{SP} j=$ Strict Preference kriteria $j$

dj $=$ rij-ri'j

$\mathrm{dmj}=1$

$\mathrm{Lj} \quad=0$

6. Menghitung Nilai Strict Preference (SP)

Perhitungan indeks preferensi yang kuat menggunakan persamaan berikut:

$\operatorname{SP}\left(i, i^{\prime}\right)=\left[\Sigma w j x \operatorname{SPj}\left(i, i^{\prime}\right) n j=1\right] / \Sigma w j n j=1$

dimana : $\mathrm{SP}=$ Strict Preference

$\mathrm{n}=$ jumlah kriteria

$w j=$ bobot kriteria $\mathrm{j}$

7. Menghitung Nilai Total Preference TP $\left(i, i^{\prime}\right)$

Persamaan untuk perhitungan total nilai indeks preferensi atau Total Preference TP $\left(i, i^{\prime}\right)$ :

$\mathrm{TP}\left(\mathrm{i}, \mathrm{i}^{\prime}\right)=\operatorname{Min}\left[1, \mathrm{WP}\left(\mathrm{i}, \mathrm{i}^{\prime}\right)+\mathrm{SP}\left(\mathrm{i}, \mathrm{i}^{\prime}\right)\right]$

8. Menghitung Nilai Entering dan Leaving Flow

Perhitunganarah aliranyang keluar dan masuk menggunakan persamaan seperti berikut:

Arah keluar (positif) untuk alternatif $\mathrm{i}$ :

$\varphi+(\mathrm{i})=1 \mathrm{~m}-1 \quad \Sigma \mathrm{TP}\left(\mathrm{i}, \mathrm{i}^{\prime}\right)\left(\mathrm{i} \neq \mathrm{i}^{\prime}\right) \mathrm{mi}^{\prime}=1$

Arah masuk (negatif) untuk alternatif $i$ :

$\varphi-(i)=1 m-1 \sum T P\left(i^{\prime}, i\right)\left(i \neq i^{\prime}\right) m i^{\prime}=1$

dimana : $\quad i=$ alternatif

i' = alternatif yang dipasangkan

$\mathrm{m}=$ jumlah alternatif

$\mathrm{n}=$ jumlah kriteria

Aliran keluar mengungkapkan berapa banyak alternatif mendominasi alternatif lain, sedangkan aliran yang masuk menunjukkan berapa banyak alternatif didominasi oleh alternatif lain.

9. Menghitung Net Flow

Perhitungan dari aliran perangkingan $\varphi($ i) untuk setiap alternatif lainnya: $\varphi(i)=\varphi+(i)-\varphi-(i)(11)$

10. Perangkingan alternatif berdasarkan $\varphi(i)$ tertinggi. Penentuan peringkat semua alternatif yang dipertimbangkan tergantung pada nilai-nilai dari $\varphi(i)$. Semakin tinggi nilai dari $\varphi(i)$, maka semakin baik pula alternatifnya. Dengan demikian, alternatif terbaik adalah alternatif yang memiliki nilai $\varphi(i)$ tertinggi.[4]

\subsection{Kepala Desa}

Kepala Desa Kepala desa berkedudukan sebagai pimpinan dan bertanggung jawab penyelenggaraan pemerintahan desa. Kepala desa bertindak sebagai lembaga Eksekutif dalam pemerintahan desa untuk dapat menjalankan roda pemerintahan desa. Kepala desa dipilih langsung oleh masyarakat desa melalui pemilihan kepala desa (Pilkades) yang bersifat langsung bila masa pemerintahan kepala desa terlah berakhir.Kepala desa memegang jabatan selama 6 (enam) tahun dan kemudian dapat dipilih kembali untuk 1 (satu) kali periode masa jabatan berikutnya.

\section{HASIL DAN PEMBAHASAN}

Pemilihan kepala desa (pilkades) di Desa kec. Lubuk pakam pada dasarnya sama dengan pilkades di desa-desa yang lain. Pengalaman yang muncul pada saat diadakannya pemilihan kepala desa di kec. Lubuk pakam yang dilakukan pada periode sebelumnya memberikan pelajaran berguna untuk memperbaiki kinerja pemimpin desa agar meningkatkatkan kemajuan suatu desa, Hal tersebut penting karena penyelenggaraan pemerintahan desa yang berdaya guna dan berhasil guna dengan pemberdayaan seluruh masyarakat, hanya akan terwujud manakala. Kritik dan saran yang diterima masyarakat dari proses pemilihan kepala desa terbaik dapat dijadikan bahan analisa 
masalah untuk dijadikan bahan referensi pemecahan masalah yang terjadi. Masalah yang timbul dapat dikategorikan kedalam masalah sarana penunjang dan kesalahan manusia (human error).

Masalah sarana penunjang menjadi prioritas utama dalam perbaikan mutu proses pemilihan kepala diperiode selanjutnya. Masalah yang dihadapi adalah pada proses pemilihan kepala desa hanya berpatokan kepada hal tententu sebagai bahan acuan dalam pemilihan kepala desa terbaik. Faktor kesalahan manusia terjadi berhubungan dengan sarana penunjang yang disediakan. Kesalahan manusia terjadi karena beberapa faktor, antara lain :

1. Warga desa kurang mengetahui dan mengenal sosok kepala desa yang akan memimpin mereka.

2. Dari setiap kriteria-kriteria merupakan salah satu demokrasi pemilihan untuk menentukan pemimpin desa dalam meningkatkatkan kemajuan suatu desa

\subsection{Analisa Penerapan Metode EXPROM II}

Sistem penentu pemilihan kepala desa terbaik pada Desa kec. Lubuk pakam merupakan sistem yang sederhana, dimana bagian pemilihan memberikan laporan berdasarkan pada setiap kriteria-kriteria kepala desa serta program pengambilan keputusan. Berdasarkan laporan tersebut, sebagai bahan pertimbangan masyarakat dalam memilih kepala desanya. Kriteria-kriteria penentuan pemilihan kepala desa terbaik yang telah ditetapkan antara lain :

Tabel 1. Kriteria

\begin{tabular}{clc}
\hline Kode Kriteria & \multicolumn{1}{c}{ Nama Kriteria } & Bobot \\
\hline C1 & Segi kemampuan (SK) & $40 \%$ \\
C2 & Segi sosialisasi (SS) & $20 \%$ \\
C3 & Segi pergaulan (SP) & $20 \%$ \\
C4 & Segi bermasyarakat (SB) & $10 \%$ \\
C5 & Segi kepribadian (SKP) & $10 \%$ \\
\hline
\end{tabular}

Keterangan :

Kriteria dari segi kemampuan memiliki bobot $40 \%$ karena merupakan kompetensi individu kelebihan 1 tingkat/level atau tingkat kemampuan menjadi pemimpin desa. Kriteria dari segi sosialisasi memiliki bobot $20 \%$ karena merupakan kompetensi individu kurang dari 3 tingkat/level atau kurang pendekatan bersosialisasi kepada masyarakat. Kriteria dari segi pergaulan memiliki bobot $20 \%$ karena merupakan kompetensi individu kurang dari 3 tingkat/level kurang pergaulan kepada masyarakat.Kriteria dari segi bermasyarakat memiliki bobot 10\% karena merupakan kompetensi individu kurang dari 4 tingkat/level atau kurang bermasyarakat.Kriteria dari segi kepribadian memiliki bobot $10 \%$ karena merupakan kompetensi individu kurang dari 4 tingkat/level atau kurang kepribadian menjadi pemimpin desa.

Alternatif-alternatif yang akan diberikan dalam pemilihan kepala desa terbaik antara lain seperti pada tabel 2 di bawah ini :

Tabel 2. Alternatif

\begin{tabular}{ll}
\hline Kode & Nama Alternatif \\
\hline A1 & Arif \\
A2 & Budi santoso \\
A3 & Feri \\
A4 & Baharudin \\
A5 & Rianto \\
\hline
\end{tabular}

Nilai alternatif untuk setiap kriteria dengan menerapkan metode EXPROM II terlihat seperti pada tabel 4.3 sebagai berikut :

Tabel 3. Tabel Nilai Alternatif

\begin{tabular}{lccccc}
\hline \multicolumn{1}{c}{ Alternatif } & \multicolumn{5}{c}{ Kriteria } \\
\cline { 2 - 6 } & SK & SS & SP & SB & SKP \\
\hline Arif & 0,5 & 0 & 30 & 1 & 1 \\
Budi santoso & 0,10 & 0 & 22,5 & 1 & 0 \\
Feri & 0 & 0,5 & 0 & 0 & 1 \\
Baharudin & 0,8 & 0,2 & 0 & 0 & 1 \\
Rianto & 0,12 & 0 & 22,5 & 1 & 0 \\
\hline
\end{tabular}

The Extended Promethee II (EXPROM II) yang dikembangkan oleh Diakoulaki dan Koumoutsosa adalah versi modifikasi Promethee II yaitu perbandingan deviasi atau jarak antar alternatif berpasangan untuk setiap kriteria.

Dalam metode ini, nilai relatif dari salah satu alternatif dari yang lain didefinisikan oleh dua indeks preferensi. Pertama adalah indeks preferensi yang lemah berdasarkan agregat atau selisih kriteria, sebagaimana 
ditentukan dalam Premethee II. Preferensi satu alternatif dengan alternatif yang lain untuk semua kriteria. Perhitungan net flow atau aliran bersih sebuah alternatif ditentukan berdasarkan penjumlahan leaving dan entering flow.

Langkah-langkah dalam menyelesaikan permasalahan untuk kasus pemilihan kepala desa terbaik dengan menerapkan metode EXPROM II antara lain :

1. Membuat matriks keputusan.

$\left[\begin{array}{lllll}0,05 & 0 & 30 & 1 & 1 \\ 0,10 & 0 & 22,5 & 1 & 0 \\ 0 & 0,5 & 0 & 0 & 1 \\ 0,08 & 0,02 & 0 & 0 & 1 \\ 0,12 & 0 & 22,5 & 1 & 0\end{array}\right]$

2. Normalisasi matriks keputusan

Normalisasi matriks keputusan merupakan proses perhitungan untuk setiap rij

dari matriks keputusan dengan cara mengurangkannya dengan min atau max (xij) sesuai dengan jenis kriteria, segi kemampuan atau cost kemudian membaginya dengan selisih max(xij) dan min (xij). Berikut penjabaran proses

perhitungan normalisasi matriks keputusan :

C1: Segi kemampuan (SK)

$\mathrm{rij}=[\mathrm{xij}-\min (\mathrm{xij})] /[\max (\mathrm{xij})-\min (\mathrm{xij})]$

dimana : $i=$ alternatif

$\mathrm{j}=$ kriteria

r11 $\frac{[0,05-0]}{[0,125-0]}=\frac{0,05}{0,125}=0,4$

Setelah proses perhitungan normalisasi matriks selesai sampai r55 maka diperoleh hasil matriks keputusan yang ternormalisasi seperti di bawah ini :

$\left[\begin{array}{lllll}0,4 & 0 & 1 & 1 & 1 \\ 0,8 & 0 & 0,75 & 1 & 0 \\ 0 & 1 & 0 & 0 & 1 \\ 0,64 & 0,4 & 0 & 0 & 1 \\ 1 & 0 & 0,75 & 1 & 0\end{array}\right]$

3. Menentukan nilai Preferensi $P j\left(i, i^{\prime}\right)$

Jenis preferensi adalah preferensi kriteria biasa.Nilai preferensi diperoleh berdasarkan perbandingan selisih nilai rij dan ri'j atau nilai alternatif yang akan dipasangkan.

$\operatorname{Pj}\left(\mathrm{i}, \mathrm{i}^{\prime}\right)=0$ if rij $\leq \mathrm{ri}^{\prime} \mathrm{j}$

$\operatorname{Pj}\left(i, i^{\prime}\right)=($ rij-ri'j) if rij $>$ ri'j

Dimana : $\mathrm{i}=$ alternatif

i'=alternatif yang akan dipasangkan

C1: Segi kemampuan (SK)

$\mathrm{r} 11 \leq \mathrm{r} 21, \mathrm{P} 1(1,2)=0$

$\mathrm{r} 11>\mathrm{r} 31, \mathrm{P} 1(1,3)=0,4-0=0,4$

$\mathrm{r} 11 \leq \mathrm{r} 41, \mathrm{P} 1(1,4)=0$

Nilai $P j\left(i, i^{\prime}\right)$ antar alternatif berpasangan seperti pada tabel di bawah ini :

Tabel 4. Tabel Nilai Preferensi

\begin{tabular}{llllll}
\hline Alternatif berpasangan & SK & PE & SP & SB & SKP \\
\hline$P j(1,2)$ & 0 & 0 & 0,25 & 0 & 0 \\
$P j(1,3)$ & 0,4 & 0 & 1 & 1 & 0 \\
$P j(1,4)$ & 0 & 0 & 1 & 1 & 0 \\
$P j(1,5)$ & 0 & 0 & 0,25 & 0 & 0 \\
$P j(2,1)$ & 0,4 & 0 & 0 & 0 & 1 \\
$P j(2,3)$ & 0,8 & 0 & 0,75 & 1 & 1 \\
$P j(2,4)$ & 0,16 & 0 & 0,75 & 1 & 1 \\
$P j(2,5)$ & 0 & 0 & 0 & 0 & 0 \\
$P j(3,1)$ & 0 & 1 & 0 & 0 & 0 \\
$P j(3,2)$ & 0 & 1 & 0 & 0 & 0 \\
$P j(3,4)$ & 0 & 0,96 & 0 & 0 & 0 \\
$P j(3,5)$ & 0 & 1 & 0 & 0 & 0 \\
$P j(4,1)$ & 0,24 & 0,04 & 0 & 0 & 0 \\
$P j(4,2)$ & 0 & 0,04 & 0 & 0 & 0 \\
$P j(4,3)$ & 0,64 & 0 & 0 & 0 & 0 \\
$P j(4,5)$ & 0 & 0,04 & 0 & 0 & 0 \\
\hline
\end{tabular}


4. $\quad$ Menghitung nilai $W P\left(i, i^{\prime}\right)$

\begin{tabular}{llllll}
\hline$P j(5,1)$ & 0,6 & 0 & 0 & 0 & 1 \\
$P j(5,2)$ & 0,2 & 0 & 0 & 0 & 0 \\
$P j(5,3)$ & 1 & 0 & 0,75 & 1 & 1 \\
$P j(5,4)$ & 0,36 & 0 & 0,75 & 1 & 1 \\
\hline
\end{tabular}

$W P\left(i, i^{\prime}\right)$ atau weak preference $\left(i, i^{\prime}\right)$ adalah preferensi lemah antar alternatif berpasangan.

$\mathrm{WP}\left(\mathrm{i}, \mathrm{i}^{\prime}\right)=[\Sigma \mathrm{wjxPj}(\mathrm{i}, \mathrm{i}) \mathrm{nj}=1] \Sigma \mathrm{wj}$

5. Menghitung nilai $\operatorname{SPj}\left(i, i^{\prime}\right)$

$\operatorname{SPj}\left(i, i^{\prime}\right)$ atau Strict Preference $j\left(i, i^{\prime}\right)$ adalah preferensi kuat antar alternatif berpasangan untuk setiap kriteria $j$.

6. Menghitung nilai $S P\left(i, i^{\prime}\right)$

$S P\left(i, i^{\prime}\right)$ atau Strict Preference ( $\left.i, i^{\prime}\right)$ adalah indeks preferensi kuat antar alternatif berpasangan $\left(i, i^{\prime}\right)$.

$\operatorname{SP}\left(\mathrm{i}, \mathrm{i}^{\prime}\right)=\left[\Sigma \mathrm{wjxSPj}\left(\mathrm{i}, \mathrm{i}^{\prime}\right) \mathrm{nj}=1\right] / \Sigma \mathrm{wj}$

7. Menghitung nilai $S B\left(i, i^{\prime}\right)$

$\mathrm{SB}\left(\mathrm{i}, \mathrm{i}^{\prime}\right)=\operatorname{Min}\left[1, \mathrm{WP}\left(\mathrm{i}, \mathrm{i}^{\prime}\right)+\mathrm{SK}\left(\mathrm{i}, \mathrm{i}^{\prime}\right)\right]$

Nilai $W P\left(i, i^{\prime}\right), S P\left(i, i^{\prime}\right)$ dan $S B\left(i, i^{\prime}\right)$ seluruh alternatif berpasangan dapat dilihat seperti pada tabel di bawah ini :

Tabel 5. Tabel Nilai $W P, S P$ dan SB

\begin{tabular}{llll}
\hline Alternatif berpasangan & $W P(i, i)$ & $S P(i, i)$ & $S B(i, i)$ \\
\hline$(1,2)$ & 0,05 & 0,05 & 0,1 \\
$(1,3)$ & 0,46 & 0,46 & 0,92 \\
$(1,4)$ & 0,3 & 0,3 & 0,6 \\
$(1,5)$ & 0,05 & 0,05 & 0,1 \\
$(2,1)$ & 0,26 & 0,26 & 0,52 \\
$(2,3)$ & 0,67 & 0,67 & 1 \\
$(2,4)$ & 0,414 & 0,414 & 0,828 \\
$(2,5)$ & 0 & 0 & 0 \\
$(3,1)$ & 0,2 & 0,2 & 0,4 \\
$(3,2)$ & 0,2 & 0,2 & 0,4 \\
$(3,4)$ & 0,192 & 0,192 & 0,384 \\
$(3,5)$ & 0,2 & 0,2 & 0,4 \\
$(4,1)$ & 0,104 & 0,104 & 0,208 \\
$(4,2)$ & 0,008 & 0,008 & 0,016 \\
$(4,3)$ & 0,256 & 0,256 & 0,512 \\
$(4,5)$ & 0,008 & 0,008 & 0,016 \\
$(5,1)$ & 0,256 & 0,256 & 0,512 \\
$(5,2)$ & 0,008 & 0,008 & 0,016 \\
$(5,3)$ & 0,34 & 0,34 & 0,68 \\
$(5,4)$ & 0,08 & 0,08 & 0,16 \\
$(5,3)$ & 0,75 & 0,75 & 1 \\
$(5,4)$ & 0,494 & 0,494 & 0,988 \\
\hline
\end{tabular}

8. $\quad$ Menghitung $\varphi+(i) \operatorname{dan} \varphi$-(i)

Menghitung $\varphi+(\mathrm{i})$

$\varphi+(\mathrm{i})=1 \mathrm{~m}-1 \Sigma \mathrm{TP}\left(\mathrm{i}, \mathrm{i}^{\prime}\right) \mathrm{ii}^{\prime}=1\left(\mathrm{i} \neq \mathrm{i}^{\prime}\right)$

Menghitung $\varphi$-(i) $\varphi$-(i) $=1 \mathrm{~m}-1 \Sigma \mathrm{TP}\left(\mathrm{i}^{\prime}, \mathrm{i}\right) \mathrm{ni}^{\prime}=1\left(\mathrm{i} \neq \mathrm{i}^{\prime}\right)$

9. $\quad$ Menghitung $\varphi(i) \varphi(i)=\varphi+(i)-\varphi$-(i)

10. Perangkingan alternatif berdasarkan $\varphi(i)$ tertinggi.

Perangkingan alternatif berdasarkan nilai $\varphi(i) s e p e r t i$ pada tabel di bawah ini :

Tabel 6. Perangkingan Alternatif

\begin{tabular}{lllll}
\hline Alternatif & $\varphi+(\mathrm{i})$ & $\varphi-(\mathrm{i})$ & $\varphi(\mathrm{i})$ & Rank \\
\hline Arif & 0,43 & 0,452 & $-0,022$ & 3 \\
Budi santoso & 0,587 & 0,169 & $-0,418$ & 2 \\
Feri & 0,396 & 0,396 & $-0,462$ & 4 \\
Baharudin & 0,188 & 0,7 & $-0,512$ & 5 \\
Rianto & 0,707 & 0,129 & 0,578 & 1 \\
\hline
\end{tabular}

Keterangan :

$$
\text { Rianto }
$$

Dari alternatif Arif mendapatkan nilai berdasarkan dari kriteria yang ditentukan pada nilai $\varphi(i)$ tertinggi dengan nilai -0,022 dengan predikat ranking 3.Dari alternatif Budi santoso mendapatkan nilai berdasarkan dari kriteria 
yang ditentukan pada nilai $\varphi($ i) tertinggi dengan nilai $-0,418$ dengan predikat ranking 2.Dari alternatif Feri mendapatkan nilai berdasarkan dari kriteria yang ditentukan pada nilai $\varphi(i)$ tertinggi dengan nilai $-0,462$ dengan predikat ranking 4.Dari alternatif Baharudin mendapatkan nilai berdasarkan dari kriteria yang ditentukan pada nilai $\varphi($ i) tertinggi dengan nilai -0,512 dengan predikat ranking 5.Dari alternatif Rianto mendapatkan nilai berdasarkan dari kriteria yang ditentukan pada nilai $\varphi(i)$ tertinggi dengan nilai -0,578 dengan predikat ranking 1 .

\section{KESIMPULAN}

Berdasarkan hasil proses perancangan dan pembuatan perangkat lunak Aplikasi Sistem Penduduk Keputusan ini, penulis menyimpulkan bahwa :

1. Sistem Penduduk keputusanyang dikembangkan guna membantu mengambil keputusan ini adalah aplikasi Untuk Pemilihan Kepala Desa Terbaik kecamatan lubuk pakam.

2. Metode EXFOROM II menghasilkan perangkingan alternatif berdasarkan nilai menghasilkan perangkingan alternatif berdasarkan nilai net flow setiap alternatif sehingga memberikan alternatif terbaik dengan net flow tertinggi net flow setiap alternatif sehingga memberikan alternatif terbaik denganmemilihkriteria-kriteria.

3. Aplikasi ini menggunakan database MySQL dan software bantuanVisual Basic.net 2008..

\section{REFERENCES}

[1] A. Romdoni, "Sistem Pendukung Keputusan Seleksi Pemilihan Calon Kepala Desa Berbasis WEB,” 2014.

[2] J. Karim, "POHUWATO PROVINSI GORONTALO,” vol. 10, no. April, pp. 86-91, 2018.

[3] A. Gazali and R. Arnie, "Model Sistem Pendukung Keputusan Pemilihan Desa Terbaik Menggunakan Metode Weighting Product," Progr. Stud. Sist. Inf., vol. 05, no. 01, pp. 925-932, 2016.

[4] Y. Silalahi, M. Mesran, T. Zebua, and S. Suginam, "PENERAPAN THE EXTENDED PROMETHEE II ( EXPROM II ) UNTUK PENENTUAN PRODUK DISKON," KOMIK (Konferensi Nas. Teknol. Inf. dan Komputer), vol. I, no. 1, 2017.

[5] F. Sains, D. A. N. Teknologi, U. Islam, N. Sultan, and S. Kasim, "MENGGUNAKAN METODE ANP ( ANALYTIC NETWORK PROCESS ) ( Studi Kasus : PT . Bank Syari' ah Mega Indonesia , KCP Baganbatu ) TUGAS AKHIR MENGGUNAKAN METODE ANP ( ANALYTIC NETWORK PROCESS ) ( Studi kasus : PT . Bank Mega Syariah Indonesia, KCP Baganbatu ) YU,” 2011.

[6] T. Limbong et al., Sistem Pendukung Keputusan: Metode \& Implementasi. Medan: Yayasan Kita Menulis, 2020.

[7] S. Kusumadewi, S. Hartati, A. Harjoko, and Retantyo Wardoyo, Fuzzy Multi-Attribute Decision Making (FUZZY MADM). 2006.

[8] Kusrini, Konsep dan Aplikasi Sistem Pendukung Keputusan. 2007.

[9] Efraim Turban and Jay E. Aronson, Decision Support System and Intelligent Systems. 2001.

[10] S. W. Pasaribu, D. P. Utomo, and Mesran, "Sistem Pendukung Keputusan Penerimaan Account Officer Menerapkan Metode EXPROM II ( Studi Kasus : Bank Sumut ),” J. Inf. Sist. Res., vol. 1, no. 3, pp. 175-188, 2020.

[11] M. Mesran, S. D. Nasution, S. Syahputra, A. Karim, and E. Purba, "Implementation of the Extended Promethee II in Upgrade Level of Mechanic," Int. J. Sci. Res. Sci. Technol., vol. 4, no. 2, pp. 125-130, 2018.

[12] Fadlina, L. T. Sianturi, A. Karim, Mesran, and A. P. U. Siahaan, "Best Student Selection Using Extended Promethee II Method," Int. J. Recent Trends Eng. Res., vol. 3, no. 8, pp. 21-29, 2017

[13] A. P. Pratidina, M. Mesran, and P. Ginting, "SISTEM PENDUKUNG KEPUTUSAN KELAYAKAN PESERTA UNTUK MENGIKUTI PROSES PELELANGAN BARANG DAN JASA PADA PEGADAIAN MENERAPKAN METODE EXPROM II," KOMIK (Konferensi Nas. Teknol. Inf. dan Komputer), vol. I, pp. 242-247, 2017.

[14] D. Assrani, Mesran, R. D. Sianturi, Yuhandri, and A. Iskandar, "SISTEM PENDUKUNG KEPUTUSAN PEMILIHAN GURU PRODUKTIF PESERTA PELATIHAN ASESOR KOMPETENSI LSP P1 SMK SWASTA DWIWARNA MEDAN MENGGUNAKAN METODE THE EXTENDED PROMETHEE II (EXPROM II) | Assrani | KOMIK (Konferensi Nasional Teknologi Informasi dan Komputer)," in KOMIK (Konferensi Nasional Teknologi Informasi dan Komputer), 2018, vol. 2 , no. 1.

[15] K. Andryan, S. Effendi, E. Santoso, and N. Hidayat, "Implementasi Metode TOPSIS Untuk Penentuan Finalis Duta Wisata Joko Roro Kabupaten Malang ( Studi Kasus : Paguyuban Joko Roro )," vol. 2, no. 2, 2018

[16] Mesran, K. Ulfa, and R. Manurung, "Penerapan Exprom II Dalam Menentukan Gabungan Kelompok Tani Terbaik Tingkat Kabupaten," PETIR J. Pengkaj. dan Penerapan Tek. Inform., vol. 12, no. 2, pp. 281-291, 2019. 